\title{
HIV/AIDS in Papua New Guinea: A reality check
}

An analysis of political statements, government reports, scientific debate and the remarks of international health officials on the HIV/AIDS epidemic in Papua New Guinea. This commentary points to a grim future unless decisive strategies are implemented now and not later.

\section{TREVOR CULLEN}

Edith Cowan University, Western Australia

7 HE TIME for doubt is over. Several statements by various political figures and health officials in 2004 and 2005 have highlighted an ominous increase in HIV infections throughout PNG. The country's Health Minister, Melchior Pep, interviewed by the author in July 2004 at the 15th annual International AIDS conference in Bangkok, said his country anticipated a massive rise in the number of HIV infections: 'We're sitting under a devastating time bomb that is exploding as we speak' (Pep, 2004). A month later, 16 political leaders representing the Pacific region gathered in Samoa for the annual Pacific Islands Forum. They expressed a similar concern about PNG and in the same month, Dr Yves Renault, the World Health Organisation (WHO) representative in PNG, estimated that HIV infections in PNG could reach one million by 2015 .

WHO estimates that two percent of PNG's population is HIV positive ... which means we have 100,000 people living with HIV. Our judgement is that, given the current level of infection and the rate of increase, it is possible that the number of infections could reach one million in 10-15 years unless decisive action is taken (Renault, 2004).

Dr Renault, who spent 16 years as an WHO representative in Sub-Saharan Africa, said that HIV infections among patients at Port Moresby General 
Hospital had reached nearly 20 percent and that the country was likely to experience an African-style epidemic.

Renault's remarks are supported by other prominent people. David Gordon-Macleod, the British High Commissioner in PNG, linked the HIV epidemic in PNG with the one in Sub-Saharan Africa, where in some countries up to one-quarter of the population is living with the virus.

I have a sense that this country is more predisposed to what has already happened in southern Africa. The reasons include lack of development, tribalism and cultural diversity, the country's difficult geography, the culture of violence towards women, the promiscuity, the lack of medical doctors and the dependency on AIDS funding from outside (Gordon Macleod, 2004).

The High Commissioner added that the figures for HIV/AIDS in the country were misleading: 'These are clearly minimal statistics and we're probably talking about several times the actual truth in reality' (Macleod, 2004). Clement Malau, former director of the National AIDS Council Secretariat in Port Moresby, insists the massive epidemic of HIV/AIDS in many Sub-Saharan African countries, such as Zambia, Malawi and Zimbabwe-where HIV infection rates are as high as 25 percent in each country - could be repeated in PNG. 'Given the current situation in PNG, we could go the same way as many Sub-Saharan African countries. So there's need for a more aggressive lead from government to fight this disease. Innovative long-term strategies must be found and implemented' (Malau, 2005).

Speaking to a group of Papua New Guinean parliamentarians in the country's capital, Port Moresby, in mid-February 2005, Dr Peter Piot, executive director of the United Nations Programme to combat the spread of HIV (UNAIDS), re-emphasised Malau's plea for strong and committed leadership:

There should be a united front that cuts across all boundaries in the fight against the AIDS epidemic as it is about the survival of your nation... And the choice for you is also clear to me. You have an emerging epidemic and it is either you act now and stop the epidemic in its infancy, or pay a very high price much later (Piot, 2005). 
Piot's remarks re-echo an earlier statement he made on HIV/AIDS in PNG in 2004:

The history of the AIDS epidemic has taught us that once things start moving, it's like a snowball and it's going to get worse and worse... PNG needs a very vigorous response otherwise, it will go the African way. And PNG has everything that's wrong - lots of migration within the country, family disruption within the towns and villages, a lot of sexually transmitted diseases and a sexual culture that makes HIV spread very rapidly (Piot, 2004).

Dr Banare Bun, chair of the special PNG parliamentary committee on HIV/ AIDS, is even blunter: 'AIDS is slowly but surely eating away the population of PNG and before long, half of the population will be gone' (Post-Courier, 14 March 2005). He added that 85 percent of the rural population still lacked knowledge of HIV. However, UNAIDS representative in PNG, Dr Nil Plange, offers some hope in a seemingly desperate situation: 'If two percent of the country's population is infected with HIV and 98 percent is not, we have to protect this group which is the majority. But to date our efforts are not reaching the provinces and rural areas' (Plange, 2005).

These remarks challenge not only politicians but also business, religious, medical, media, legal, civil leaders and non-government organisations to find appropriate responses to this rapidly expanding public health epidemic. While certain individuals and organisations have spoken persistently about the dangers of the epidemic and called for an urgent and determined response, there is need for a larger multi-pronged approach that involves all sectors of society. And promoting prevention is seen by the WHO as a key approach in attempts to limit the worrying rise of HIV infections throughout PNG and in several other Pacific countries. But this has proved extremely difficult to implement.

\section{HIV in PNG: Current debates}

What worries health experts about the HIV/AIDS epidemic in PNG is that certain sexual behavioural practices remain widespread and unchallenged. A survey conducted by the Medical School at the University of PNG in 2004 on sexual behaviour and the prevalence of sexually transmitted diseases, revealed some disturbing findings. Professor Mathias Sapuri, dean of the University 
of PNG's School of Medicine and Health Sciences, highlighted some alarming trends:

We believe that 45-55 percent of PNG men in the sexually active age range of 19-45 are having sex with more than one partner, possibly multiple partners. And it's the combination of multiple sex partners and the increasing prevalence of sexually transmitted infections (STIs) that puts Papua New Guineans most at risk of a devastating social catastrophe...These are not nightmare stories designed to frighten people...these are medical facts of an epidemic already deeply entrenched in our society (Sapuri, 2004).

An earlier survey in 2002 targeted female sex workers at 29 sites in Port Moresby and interviewed 246 of them. Seventy percent of the respondents said that they did not use a condom because clients would pay more for unprotected sex, while 15 percent were married and 10 percent had remarried. (Post-Courier, 4 September 2003). These findings point to the complex nature of the sexual culture operating within the country. A report by UNAIDS and WHO on the global AIDS epidemic at the end of 2004 confirmed this complexity when it stated that the combination of widespread commercial sex and multiple non-commercial partners seen in PNG is ominous, since it enables the epidemic to assume much greater proportions. The report also details how a high incidence of rape, sexual aggression and other forms of violence against women appears to be aiding the epidemic's growth (UNAIDS/ WHO, 2004).

The director of PNG's National AIDS Council (NAC), Dr Ninkama Mioya, worries that current efforts to lessen infection rates will probably fail. Interviewed by the author in late October 2005 at the first Pan Pacific Regional Conference on HIV in Auckland, he argued that:

Getting the message across to people is not a problem, but it is changing attitudes and behaviour that is the issue. People know AIDS has no cure but still continue to have sex without a condom... We can say and do all we want, but if people at the individual level can't respond positively to prevent HIV, all we've done will count for nothing (Moiya, 2005).

The head of World Vision in PNG, Don Bradford, agrees and states: 'We can 158 PACIFIC JOURNALISM REVIEW 12 (1) 2006 
flood the market place with condoms and all sorts of other programmes but if people's hearts and minds do not change - then we are simply wasting out time' (Post-Courier, 23 September 2004).

Former medical specialist for WHO in the Pacific region, Michael O'Leary, urges a two-pronged attack: First, greater attention to prevention, diagnosis and treatment of sexually transmitted infections (STIs) which are very common in PNG and the Pacific region. This, he argues, can contribute towards reducing the risk of HIV transmission. Secondly, he calls for more research into understanding the dynamics of sexual behaviour in the Pacific as a way to tackle high rates of risk-taking behaviour. 'Sex is everywhere but the networks and specific patterns and behaviours vary widely' (O'Leary, 2004).

Some researchers look to the use of condoms as an immediate practical solution. When the HIV/AIDS epidemic emerged in developing countries in the mid-1980s, many of those involved with prevention programmes believed condoms to be the most effective means to curb the spread of HIV. Recent analysis, however, has shown that while condom use may have played a significant role in reducing HIV infection in highly vulnerable populations such as sex workers and their clients, they have little impact on the general population in high prevalence countries. It was found that married couples or regular partners seldom use condoms, and HIV rates have continued to rise along with the sale of condoms in countries such as Kenya, South Africa and Botswana (Mckee, Bertrand \& Becker-Benton, 2004, p. 89).

Take Uganda as an example. After a decade of fighting the virus on all fronts, in December 1996 Uganda became the first country to report declining trends in HIV infection. What caused HIV infections to fall? Available evidence suggests that the main reason was a substantial change in sexual behaviour, particularly a reduction in regular partners. 'Comparisons with neighbouring countries suggest that changes in the numbers and types of partners have much more to do with the decline in HIV infections in Uganda than do the rates of condom use which were lower in Uganda than in other African countries in the mid-1990s' (Hearst and Chen quoted in McKee et al 2003, p. 92). This claim, that the apparent decline in HIV infections appears to have more to do with reduction in casual partners than with increased condom use, is supported by Grulich and Kaldor (2002).

However, there is no simple answer to the question of what works best 
and some researchers argue that there should be a more balanced approach. For example, an in-depth review of what happened in Uganda concluded that the $\mathrm{A}$ and $\mathrm{B}$ prevention programmes (Abstinence and Be faithful to one partner) have been more important than $\mathrm{C}$ (use a condom) in achieving success in Uganda, although all three factors may now be responsible for sustaining those achievements (McKee et al., 2004, p. 90). A Ugandan-style campaign that emphasised partner reduction would probably not have worked in Thailand. Likewise, a Thai-style programme emphasising condom use in commercial sex and the prevention for injecting drug users would not have worked in Uganda (Mckee et al., 2004, p. 92). It seems each country needs to tailor its approach to local needs. In PNG, there is little intravenous drug injecting and it is difficult to buy condoms. Mix this together with the cultural problems that prevent condom use such as in the case of women who cannot insist on their use even if they think their partner has been unfaithful. These factors strongly point to the use of a Ugandan-style campaign in PNG. Piot (2005) encouraged PNG political leaders he met there in early 2005 to look at the Ugandan model as a way to tackle the emerging epidemic within the country.

With the main mode of HIV transmission in PNG through heterosexual relations, it is in a sense more dangerous for the whole population. Some countries like Uganda, however, have been able to lower the number of new infections, not by sophisticated technology or drugs, but by massive social mobilisation. That is the key (Piot, 2005).

\section{Cultural factors preventing change}

If changing attitudes and sexual behaviour are so fundamental to slow the spread of the epidemic, why is there so much indifference and resistance to this strategy? As yet, there is no substantial study on the reasons for this in PNG. Researchers, however, have examined this problem in parts of Africa. Caldwell (1999) puts forward several reasons for limited sexual behavioural change in Sub-Saharan Africa, which by 1999 had already passed 20 million infections. The researcher noted that in countries such as the Netherlands and Australia, people responded to the warnings about HIV/AIDS and dramatically changed their sexual practices. The example of anal syphilis is used: it fell by 90 percent in the first year that HIV/AIDS was seriously under discussion (Caldwell, 1999, p. 242).

This was not the case in many African countries. Caldwell's research on HIV/AIDS in Sub-Saharan Africa began in the late 1980s and he points to 160 PACIFIC JOURNALISM REVIEW 12 (1) 2006 
several common cultural constraints that prevented an aggressive and coordinated response to tackling the disease. Firstly, traditional pre-marital sexual practices and a widespread social taboo prevent discussion of sex. Boys are often motivated to boast to their male friends about the numbers of conquests before marriage. And male dominance in most aspects of sexual decisionmaking means that girls have no answer to their boyfriends' taunts. Failure to engage in sexual relations shows a lack of love. Then, there is the fear of testing positive because it would bring shame and possible danger to the rest of the family. The result is that a great majority of the people do not want to know their status and do not want to be tested. Also, many people feel helpless to change the course of events because they believe that witchcraft or other supernatural forces play at least some part in causing HIV. With sickness of any sort there is usually a cause and a causer which shows that the person infected has no real control of his or her situation. This may explain to some extent why death is so readily accepted (Caldwell, 1999, pp. 241-256).

Other obstacles include the fact that the general public are often complacent about the crisis and people tend to look at immediate needs rather than at a virus which could develop into AIDS in ten years. And without a cure, there seems to be no point in creating further hopelessness. Matters related to sexual behaviour are rarely discussed in public because sex is still a taboo subject and the connection of HIV/AIDS to sex runs the risk of linking people with HIV/AIDS to illicit sex (Caldwell and Orubuloye, 1992, p. 1170). Cullen (1991) points to the harsh living conditions in many rural and urban areas in Africa which create a sense of helplessness and a lack of desire to protest or complain about HIV/AIDS.

People live from day to day. It is hard to interest them in some action today that could affect their lives in five to ten years. Where the next meal is coming from is more important. The fear of death is not to them such a deterrent, for in the villages, death is a part of everyday life and experience (Cullen, 1991, p. 1504).

Cullen (1992) adds that in many African countries the low status of women provides a classic example of the cultural difficulties that prevent resistance to possible HIV infection: 'It seems that many women have little control over their own lives and the health of their future babies. It is hard for them to take a stand and the less bargaining power a woman has, the harder it is to avoid

PACIFIC JOURNALISM REVIEW 12 (1) 2006161 
taking risks" (Cullen, 1992, p. 1504). Information about HIV/AIDS has to compete with ingrained cultural practices. Women are extremely vulnerable.

It is possible for a woman to suffer triple jeopardy; she may become infected herself; she may pass the infection to her baby in the womb; because women are the main carers for the sick, she carries the burden if someone close to her dies. This brings both fear and guilt. Anxiety increases when she falls sick and worries about who will look after the household or how to keep a part-time job (Cullen, 1992, p. 389).

It would not be surprising if future research on the impact of cultural factors on preventing the spread of HIV/AIDS in PNG, discovers that there are similar cultural restraints operating in the country which prevents a decisive community-based response to the epidemic. This would have important implications for current awareness and educational campaigns.

\section{Current figures for HIV infections}

Editors tend to prefer hard data rather than broad estimates or predictions. Terms such as 'potential epidemic' or 'emerging crisis' are too vague and editors may be influenced by what media researcher, Mayer (1964), referred to as the quantitative view of importance. In PNG, however, it is difficult to give the exact number of infections. One reason is the lack of an adequate national surveillance system. This was discussed at a workshop in Port Moresby in mid-November 2004, which brought together more than 80 medical and health officials from around the country. The participants asked for the establishment of HIV surveillance programs in seven more provinces and to test at least 700-800 people at higher risk in key locations. There was widespread concern that the existing system still left substantial uncertainty about the HIV/AIDS situation, thereby hampering efforts at advocacy, resources allocation and programme monitoring and evaluation (Consensus workshop, 2004).

HIV infections at antenatal clinics in some provinces have risen to above 1 percent. This, for $\mathrm{WHO}$, is the level at which a generalised epidemic is defined as occurring. But caution needs to be applied given the absence of information on HIV prevalence in pregnant women in all but a handful of the country's 20 provinces. What is not in dispute is the fact that AIDS is the leading cause of death at Port Moresby General Hospital (PMGH). Geoff

162 PACIFIC JOURNALISM REVIEW 12 (1) 2006 
Clark, WHO's nursing human resource officer in PNG, believes HIV infections are seriously understated: 'AIDS is the number one killer at PMGH and already two percent of all ante-natal cases there are HIV positive. And that's only in one place. I'd say we're looking at a much higher rate of the population being infected, not just one to two percent' (Clark, 2005).

The effect of massive infection rates will have disastrous economic consequences. A report in 2002, entitled Potential economic impact of an HIV/ AIDS epidemic in $P N G$, published by the Centre for International Economics, paints a depressing future for PNG. The study estimated that by 2020, PNG's labour force would be between 13 and 38 percent smaller than projected without HIV:

\begin{abstract}
If Papua New Guinea follows the low scenario, the working age population will be 13 percent smaller than it would otherwise have been by 2020. If PNG follows the medium pathway, the working age cohort will be smaller than 34 percent. If it follows the big scenario, it will be smaller by almost 38 per cent... The current measured HIV/AIIDS prevalence places PNG in either the low level or concentrated phase (Potential economic impact of an HIV/AIDS epidemic in PNG, 2002, pp. 8-9).
\end{abstract}

Another report was published at the end of 2004 by Australia's department of Foreign Affairs and Trade. Entitled Papua New Guinea: The Road Ahead, it continues the bleak outline of the 2002 report and analyses future economic and investment opportunities within the country. The section on demographic trends shows that PNG's population has almost doubled in size from 2.9 million at independence in 1975 to 5.5 million in 2004, growing at an average rate of 2.5 per year. Forty one percent of the population is under the age of 15 . On the same page, the latest figures for HIV infections in PNG are reported and analysed. In fact, there are three sets of figures for HIV infections in PNG, depending on whether the epidemic turns out to be on a low, medium or a high infection level. Therefore, the figures range from 0.9 percent of the population $(25,000)$ to a medium range of 1.7 percent $(45,000)$ to a worstcase scenario of 2.5 percent $(69,000)$. Whatever figures are adopted, PNG still remains the country with the highest number of HIV cases in the Pacific - higher than the combined infection rates of all the other Pacific countries put together. 
The 2004 report makes the point that HIV surveillance in the country is poor and HIV infection rates across the country are almost certainly grossly under-estimated. There is broad agreement that the incidences of HIV/AIDS in PNG have risen dramatically and on its current course, it will have a devastating economic impact on households, firms and the government. The authors of the report point to a possible collapse of the health system through massive increased demand on health sector resources. It describes the country's health system as chronically under-resourced and struggling to provide services at all levels. It is not equipped to deal with an HIV/AIDS epidemic. Lack of financial support is another hindrance. In 2003 and 2004, the direct contribution from the PNG government for HIV amounted to only K700,000 (AS350,000). While the amount allocated for HIV/AIDS in 2005 is substantially higher, the government and ultimately the people may pay a high price for the serious lack of financial support in earlier years.

Political leadership has proved a vital component in the struggle to stem the rise of HIV infections in other parts of the world. This is clear from the decline of infections in Uganda, Senegal and the Gambia where all three political leaders in these countries spoke openly and constantly about the epidemic in their own countries. This helped to lessen the sense of fear and stigma about HIV/AIDS in the local communities, and it galvanised them into action as they defined the struggle against HIV as a national cause and campaign. Therefore, let us not forget the rally call by a Pacific political leader, the former Fijian Prime Minister, Sitiveni Rabuka, and his statement on the increase of HIV/AIDS in PNG and the South Pacific region. Sadly, his metaphorical description in 1996 sounds increasingly more prophetic in 2006.

The HIV/AIDS epidemic in the Pacific is a clear enough signal that there is a storm gathering force; a storm that can become a devastating hurricane such as we have never seen before and a storm which, if we do not take the necessary precautions, we will not live through or live to regret forever (Rabuka, 1996).

\section{References}

AusAID (2002). Potential economic impacts of an HIV/AIDS epidemic in Papua New Guinea..Canberra: AusAid.

Beharrell, P. (1993). AIDS and the British Press. In Glasgow University Media Group (Eds.), Getting the message: News, truth and power. (pp. 210-249). London: Routledge.

164 PACIFIC JOURNALISM REVIEW 12 (1) 2006 
Bradford, D. (2004, September 23). Editorial in the Post Courier.

Caldwell, J. and O. Orbuloye. (1992). Under-reaction to AIDS in Sub-Saharan Africa. Social Science and Medicine. 34 (11) pp. 1169- 1182.

Caldwell, J. (1999). Reasons for limited sexual behavioral change in the Sub-Saharan African AIDS epidemic, and possible future interventions. In resistances to behavioural change to reduce HIV/AIDS infection in predominantly heterosexual epidemics in Third World countries. Canberra: Health Transition Centre.

Consensus Workshop on HIV/AIDS in Papua New Guinea (2004). Draft copy. Port Moresby: World Health Organisation. (WHO), November 17-18.

Cullen T. (1991). The AIDS battle. The Tablet, December 7, pp. 1504 -1505.

Cullen, T. (1992). Living with HIV. The Tablet, March 21, pp. 389 - 390.

Cullen, T. (2000). Press coverage of HIV/AIDS in Papua New Guinea and the South Pacific. Unpublished PhD thesis. St Lucia: University of Queensland.

Cullen, T. (2003). Press coverage of HIV/AIDS in the Pacific: Short-term view of a long-term problem. Pacific Journalism Review, (9), pp. 139-148.

Cullen, T. (2003). HIV/AIDS: Twenty years of press coverage. Australian Studies in Journalism, (12), pp. 64-88.

Cullen. T. (2005). Press coverage of HIV/AIDS in PNG: Is it sufficient to report only the news? Australian Studies in Journalism, (15), pp. 133-150.

Grulich, A. and Kaldor G. (2002). Evidence of success in HIV prevention in Africa. The Lancet. 360(9326), p. 3.

Hearst, N. and S. Chen (2003). Condoms for AIDS prevention in the developing world $-A$ review of the scientific literature. San Francisco: University of California.

Macleod, D,G. (2004, January 16). AIDS a major threat-Envoy. Post-Courier.

Malau C (2005). Former director of PNG's National AIDS Council. Interviewed by the author at the Pan Pacific Regional Conference on HIV. October 23-29 Auckland, New Zealand.

Mayer, H. (1964). The press in Australia. California: Lansdowne Press.

Mckee, N. J. Bertrand, and A. Becker-Benton (2004). Strategic communication in the HIV/AIDS epidemic. London: Sage Publications.

Moiya, N. (2005). Chairman of PNG's National AIDS Council. Interviewed by the author at the Pan Pacific Regional Conference on HIV. October 23-29 Auckland, New Zealand.

Papua New Guinea: The road ahead. (2004). Report by Department of Foreign Affairs and Trade: Economic Analytical Unit.

Pep, M. (2004). PNG's Minister of Health. Interviewed by the author at the International AIDS Congress, Bangkok, 12 July.

Piot, P. (2001). Chief Executive of the United Nations Global Programme on HIV/ AIDS (UNAIDS). Interviewed by the author at the International Congress on HIV/ AIDS in Asia and the Pacific, Melbourne, October 7.

Piot, P. (2004, March 22). UN says Pacific faces new wave of HIV with PNG on the brink of epidemic. Agence France Presse (AFP).

Piot P. (2005, February 19). Part of his speech to PNG parliamentarians as reported in The National. 
Plange, N. (2005, February 24), UNAIDS boss stresses awareness. Post-Courier. Renault, Y. (2004, September 23). WHO warns PNG of AIDS scourge. Post- Courier. Sapuri M. (2004). Interview with Professor Mathias Sapura, dean of Medicine and Health Sciences at the University of PNG. Reported in Prime magazine. Issue 16, p. 2.

The Global AIDS Epidemic (2005). Geneva: UNAIDS/WHO.

United Nations (2005). Global Figures for HIV/AIDS. Geneva: UNAIDS.

Dr Trevor Cullen is head of journalism at Edith Cowan University, Western Australia. His doctoral thesis focused on press coverage of HIV/AIDS in the South Pacific region and he has written extensively on the virus and delivered papers on the topic at international conferences in Australia, China, Egypt, Fiji, Malaysia, Papua New Guinea and New Zealand. He has also helped to organise and run several workshops on 'Reporting HIV/AIDS' for journalists in Australia, Fiji, Papua New Guinea, Samoa and Tonga.

t.cullen@ecu.edu.au

\section{Pacific}

Journalism Review

Pacific Journalism Review back copies

Back copies of Pacific Journalism Review

can be ordered from:

University Bookshop Ltd (Auckland)

www.ubsbooks.co.nz

USP Book Centre

www.uspbookcentre.com

PJR subscription details and order forms

are online at:

www.pjreview.info

166 PACIFIC JOURNALISM REVIEW 12 (1) 2006 